\title{
Longitudinal isotope ratio variations in human hair
}

\author{
KATERINA RODIOUCHKINA ${ }^{1}$, ILIA RODUSHKIN ${ }^{2}$, \\ STEVEN GODERIS $^{3}$ AND FRANK VANHAECKE ${ }^{1}$
}

${ }^{1}$ Ghent University

${ }^{2}$ ALS Laboratory Group, ALS Scandinavia AB

${ }^{3}$ Vrije Universiteit Brussel

Presenting Author: katerina.rodiouchkina@ugent.be

Determination of element concentrations and their isotopic compositions in hair is increasingly attractive in a variety of fields, due to the straightforward and non-invasive nature of the sampling and the possibility for obtaining time-resolved information via spatially resolved analysis. In this study, multielement isotopic analysis was carried out using MC-ICP-MS, focusing on $\delta^{25,26} \mathrm{Mg}, \delta^{34} \mathrm{~S}, \delta^{56,57} \mathrm{Fe}, \delta^{65} \mathrm{Cu}, \delta^{66} \mathrm{Zn},{ }^{87} \mathrm{Sr} /{ }^{86} \mathrm{Sr}$, $\delta^{114} \mathrm{Cd},{ }^{207,208} \mathrm{~Pb} /{ }^{206} \mathrm{~Pb}$. Method development relied on the use of three hair reference materials, as well as on segmented hair from 9 subjects without prior cleaning to remove external contamination. A trend towards a heavier $\mathrm{S}$ isotopic signature from the proximal to the distal end was observed for all subjects, with a maximum difference within the hair of a single subject of $1.2 \%$. Preferential losses of the lighter $\mathrm{S}$ isotopes from hair may be responsible for the trend, as also suggested by slightly lower $\mathrm{S}$ concentrations at the distal end. A similar trend was established for $\mathrm{Zn}$, with a difference ( $\Delta^{66} \mathrm{Zn}$ ) of up to $0.4 \%$ within the hair of a single subject, while a significant increase in concentration, accompanied by a shift towards a lighter isotope composition along the hair was found for $\mathrm{Cu}$. On the contrary, for $\mathrm{Fe}, \mathrm{Mg}$ and $\mathrm{Cd}$, concentrations increased approaching the distal end, with a shift towards heavier isotope compositions. Unidirectional changes in the isotope composition accompanied with an increase in element concentration along hair strands may reflect an accumulation of exogenous contamination(s). Differences in location of residence, diet and lifestyle may be responsible for observed concentration and isotope variations among the subjects tested. A notable increase in $\mathrm{Pb}$ and $\mathrm{Sr}$ concentrations towards the distal end of hair, with more radiogenic isotope ratios for these elements observed for some subjects. The isotopic composition of $\mathrm{Sr}$ and $\mathrm{Pb}$ suggests tap water as a probable main source of $\mathrm{Pb}$ and $\mathrm{Sr}$ in hair, occurring through ingestion and showering, explaining the relative stability of the ratios for individuals from the same geographical location. 